\title{
Only the Lonely: A Study of Loneliness Among University Students in Norway
}

\author{
Mari Hysing $^{\mathrm{a}}$, Keith J. Petrie ${ }^{\mathrm{b}}$, Tormod Bøe ${ }^{\mathrm{a}}$, Kari Jussie Lønning ${ }^{\text {cd }}$, Børge Sivertsen ${ }^{\text {efg }}$ \\ [a] Department of Psychosocial Science, Faculty of Psychology, University of Bergen, Bergen, Norway. [b] Department of \\ Psychological Medicine, University of Auckland, Auckland, New Zealand. [c] The Norwegian Medical Association, Oslo, \\ Norway. [d] The Student Welfare Organization of Oslo and Akershus (SiO), Oslo, Norway. [e] Department of Health \\ Promotion, Norwegian Institute of Public Health, Bergen, Norway. [f] Department of Research \& Innovation, Helse-Fonna \\ HF, Haugesund, Norway. [g] Department of Mental Health, Norwegian University of Science and Technology, Trondheim, \\ Norway.
}

Clinical Psychology in Europe, 2020, Vol. 2(1), Article e2781, https://doi.org/10.32872/cpe.v2i1.2781

Received: 2019-06-10 • Accepted: 2020-01-13 • Published (VoR): 2020-03-31

Handling Editor: Cornelia Weise, Philipps-University of Marburg, Marburg, Germany

Corresponding Author: Mari Hysing, Department of Psychosocial Science, Faculty of Psychology, University of Bergen, Post box 7807, 5020 BERGEN, Norway; +47 555886 98. E-mail: mari.hysing@uib.no

\begin{abstract}
Background: Loneliness is a major public health concern among college and university students, the evidence is inconsistent regarding whether there is an increasing trend or not. Furthermore, knowledge of the demographic determinants for loneliness are limited. The present study assesses recent trends of loneliness from 2014 to 2018, and explores demographic risk indicators of loneliness among students.

Method: Data was drawn from two waves of a national student health survey from 2014 and 2018 for higher education in Norway (the SHoT-study). In 2018, all 162,512 fulltime students in Norway were invited to participate and 50,054 students (69.1\% women) aged 18-35 years were included (response rate $=30.8 \%$ ). Loneliness was measured by "The Three-Item Loneliness Scale" (T-ILS) and one item from the Hopkins Symptom Checklist-25 (HSCL-25).

Results: Age showed a curvilinear association with loneliness, with the youngest and oldest students reporting the highest level of loneliness across all measures. Other significant demographic determinants of loneliness were being female, single and living alone. There was a considerable increase in loneliness from $2014(16.5 \%)$ to $2018(23.6 \%, \mathrm{p}<.001)$, and the increase was particularly strong for males, for whom the proportion of feeling "extremely" lonely had more than doubled.

Conclusion: The high rate of loneliness and the increasing trends indicate the need for preventive interventions in the student population.
\end{abstract}




\section{Keywords}

loneliness, students, young adults, partnership status, student accomodation

\section{Highlights}

- Loneliness among Norwegian university students increased from 2014 to 2018, particularly for males.

- Students in transitional periods, both the youngest and oldest reported the most loneliness.

- Being single and living alone were risk factors for loneliness.

Loneliness reflects the subjective feeling of disconnectedness and not belonging, and is often characterized as "a perceived discrepancy between desired and actual social relationships" (Portnoy, 1983). Loneliness is associated with more health problems (Hayley et al., 2017), and has been linked to an increased mortality risk (Holt-Lunstad, Smith, Baker, Harris, \& Stephenson, 2015). Loneliness has often been thought of as a concern that peaks in older age. However, recent evidence has shown that the developmental trajectory is more U-shaped, with young adults having the highest levels of loneliness (Luhmann \& Hawkley, 2016), followed by a second peak in older age groups.

The transition from adolescence to young adulthood makes college and university students a particularly vulnerable group for feelings of loneliness (Diehl, Jansen, Ishchanova, \& Hilger-Kolb, 2018). This may be related to developmental-specific risk factors, such as moving away from home and their local community, and re-establishing new social networks. Surprisingly, the epidemiology of loneliness in young people has received scant attention. Knowledge of risk indicators and vulnerable subgroups are important in order to promote preventive actions. If loneliness is limited to, or peaks at the actual transition from moving away from home, a decline in loneliness over time should be expected among more senior students, which has been demonstrated in a German University sample (Diehl et al., 2018).

A recent UK study of 18-year-old twins found that loneliness was equally common across sexes and socioeconomic status (SES) (Matthews et al., 2019), whereas others have found both higher (Mounts, 2004) and lower (McWhirter, 1997) levels of loneliness among men. This inconsistency was also confirmed in a recent meta-analysis (Mahon, Yarcheski, Yarcheski, Cannella, \& Hanks, 2006). In the general population, loneliness is more prevalent among adults without partners (Beutel et al., 2017), and also students living alone report more loneliness compared to those living in dorms or with a partner/ friend (Diehl et al., 2018). Still, the literature remains sparse on the issue of identifying risk indicators of loneliness among young adults.

It has been suggested that the prevalence of loneliness is increasing, but very few studies have examined this over time (Cacioppo, Grippo, London, Goossens, \& Cacioppo, 
2015). A study of older Dutch people showed no change in loneliness from 2005 to 2010, with the exception of a subgroup of individuals with activity limitations, where the trend was increasing (Honigh-de Vlaming, Haveman-Nies, Groeniger, de Groot, \& van 't Veer, 2014). A similar stable pattern was observed in a Swedish study of an elderly population (Dahlberg, Agahi, \& Lennartsson, 2018). In contrast, there was a rising rate of loneliness among Danish adolescents from 1991 to 2014, with the largest increase being observed among adolescents from families with high SES (Madsen et al., 2019).

This study addressed three main questions in a large nationally representative sample of young people: (1) what demographic factors are associated with loneliness in young adult college and university students? (2) How does partnership status offer protection from feelings of loneliness? and (3) Has the rate of loneliness changed from 2014 to 2018 in this population?

\section{Method}

\section{Procedure}

The SHoT study (Students' Health and Wellbeing Study) is a national student survey for higher education in Norway. The main aim of the survey is to monitor students' health, wellbeing and psychosocial environment. The survey has been carried out three times (2010, 2014 and 2018), and the two most recent waves (2014 and 2018) were used in the present study.

The SHoT2014 study was conducted by the three largest student welfare organizations (Sammen [Bergen], Sit [Trondheim] and $\mathrm{SiO}$ [Oslo and Akershus]) in collaboration with, and with participation from, the 10 largest student welfare organizations in Norway, also targeting full-time Norwegian students < 35 years of age. Data for the SHoT2014 study were collected electronically using a web-based platform in the period from 24 February 2014 to 27 March 2014. An invitation email containing a link to an anonymous online questionnaire was sent to 47,514 randomly selected students and stratified by study institutions, faculties, and departments. The overall response rate was $28.5 \%$ and included 13,525 students.

The SHoT2018 was initiated by the three largest student welfare organizations (Sammen [Bergen and surrounding area], Sit [Trondheim and surrounding area] and $\mathrm{SiO}$ [Oslo and Akershus]), representing all student welfare organizations in Norway and done as a joint effort between these student welfare organisations and the Norwegian Institute of Public Health (NIPH). Data were collected between February 6 and April 5, 2018 and all fulltime Norwegian students aged between 18 and 35 years taking higher education (both in Norway and abroad) were invited to take part. The survey data were collected electronically through a web-based platform and some institutions allocated time during classes for the students to complete the set of questionnaires. For the SHoT2018 study, 
162,512 students fulfilled the inclusion criteria, of whom 50,054 (30.8\%) students completed the online questionnaires (Sivertsen, Råkil, Munkvik, \& Lønning, 2019).

\section{Ethics}

The authors assert that all procedures contributing to this work comply with the ethical standards of the relevant national and institutional committees on human experimentation and with the Helsinki Declaration of 1975, as revised in 2008. All procedures involving human subjects/patients were approved by the Regional Committee for Medical and Health Research Ethics in Western Norway (no. 2017/1176 [SHOT2018]). Informed consent was obtained electronically after the participants had received a detailed introduction to the study. Approvals for conducting the SHoT2014 studies were granted by the Data Protection Officer for research at the Norwegian Centre for Research Data.

\section{Instruments}

\section{Demographic Information}

All participants indicated their sex and age. In the current study, age was used both as a continuous and categorical variable, the latter employing the following age categories (18-20 years, 21-22 years, 23-25 years and 26-35 years). Participants were also asked about their relationship status (response options: "single", "girl-/boyfriend", "cohabitant", and "married/ registered partner"), as well as their accommodation status (response options: "living alone", "living with partner", "living with friends/others in a collective", and "living with parents"). Participants were categorized as an immigrant if either the student or his/her parents were born outside Norway. Finally, all students indicated if they were living or studying abroad.

\section{Loneliness}

Loneliness was measured by one item of the depression subscale of the HSCL-25 (Derogatis, Lipman, Rickels, Uhlenhuth, \& Covi, 1974) in 2014 and 2018. In the past two weeks, including today, how much have you been bothered by feeling lonely? The response alternatives were "not at all", "a little", "quite a bit", and "extremely".

In SHoT2018 loneliness was assess using an abbreviated version of the widely used UCLA Loneliness Scale, “The Three-Item Loneliness Scale (T-ILS)” (Hughes, Waite, Hawkley, \& Cacioppo, 2004). The T-ILS include the following three items, each rate along a 5-point Likert scale ("never", "seldom", "sometimes", "often”, and "very often"). For each question below, please indicate how often you have felt that way during the last year: 1) How often do you feel that you lack companionship? 2) How often do you feel left out, and 3) How often do you feel isolated from others? The T-ILS has displayed satisfactory reliability and both concurrent and discriminant validity. (Hughes et al., 2004) In addition 
to analysing each of the three T-ILS items separately, we also calculated a total score, adding the three items together. The Cronbach's alpha of the T-ILS total score was .88.

\section{Statistics}

IBM SPSS version 25 (SPSS Inc., Chicago, IL, USA) for Mac was used for all analyses. Chi-square tests and logistic regression analysis were used to examine differences in the three loneliness items across demographical characteristics. Analysis of Variance (ANOVA) were conducted to examine potential polynomial/curvilinear associations between loneliness and age group by entering quadratic terms. We also used the Curve Estimation command in SPSS to test both the linear and curvilinear association between age as a continuous variable and overall loneliness. ANOVAs were also used to examine the T-ILS total score against the demographic variables. Effect sizes (pooled SD) were calculated using the Cohen's $d$ formula (Cohen, 1988). Pearson's chi-squared tests were used to test for significant changes in loneliness over time. Missing values were handled using listwise deletion.

\section{Results}

\section{Descriptive Characteristics}

Compared to all invited students $-58.1 \%$ women $(n=93,267)$ and $41.9 \%$ men $(n=67,558)$

- the current sample included a larger proportion of women (69.1\%) than men $(30.9 \%)$.

The mean age was $23.2(S D=3.3)$.

\section{Loneliness in SHoT2018}

The response patterns of the three loneliness items are detailed in Figure 1. Almost one in four students (21\% in males and $24 \%$ in females) felt that they lacked companionship "often" or "very often". The corresponding estimates for the items "feeling left out" and "feeling isolated" were slightly lower, with $14 \%-15 \%$ in women and $17-18 \%$ in men (see Figure 2 for details). One in ten students (10.1\%) reporting "often/very often" on all three items (females: $10.6 \%$ and males: $8.8 \%$ ). All sex differences were statistically significant ( $p$ $<.001)$. 


\section{Figure 1}

Response Pattern of the Three Loneliness Items in the T-ILS Among College/University Students in the SHoT2018 Study

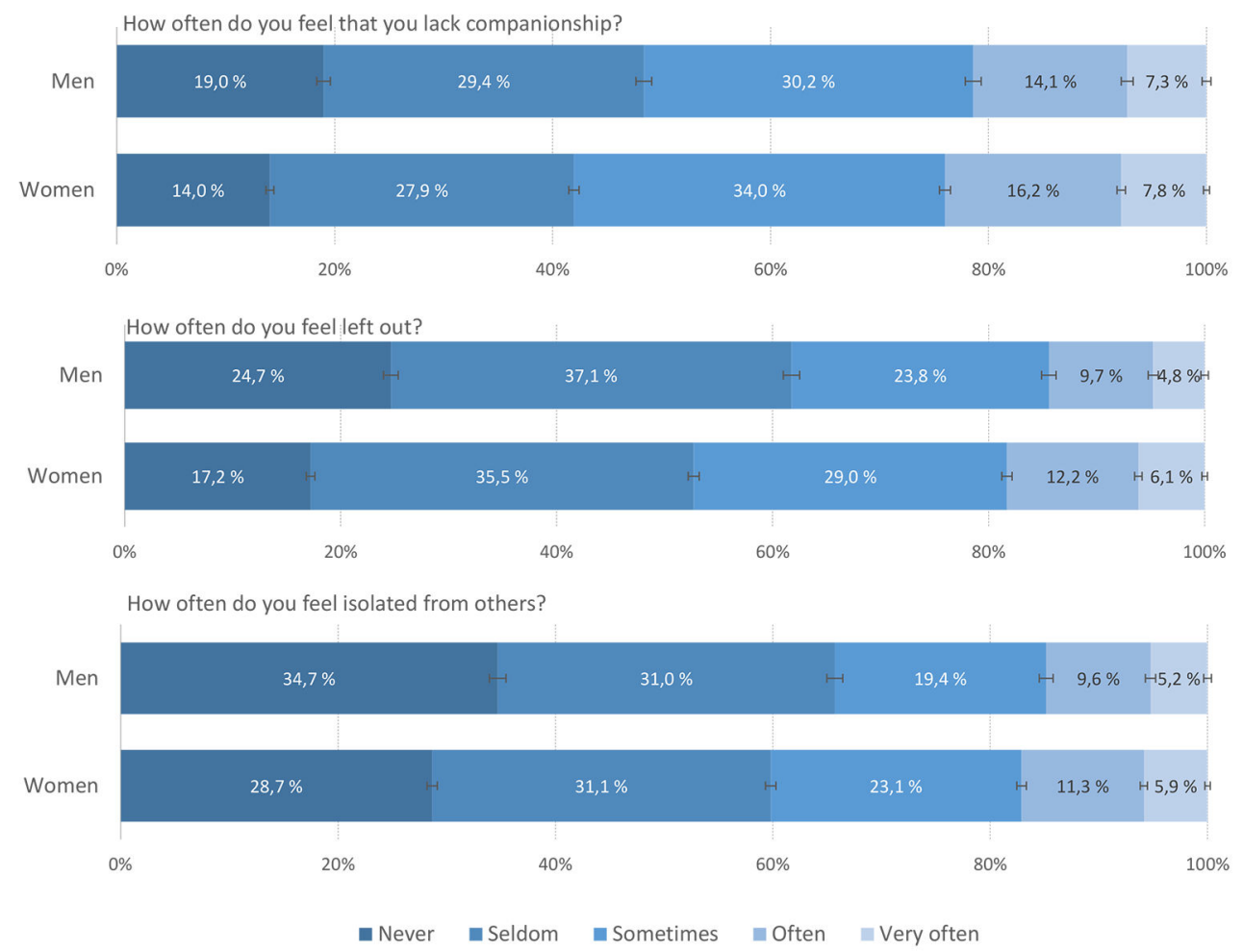

Note. Error bars represent $95 \%$ confidence intervals.

\section{Loneliness and Age}

Figure 2 shows the prevalence of the three loneliness items across the different age groups. As indicated by the dotted trend lines, there was a significant curvilinear relationship (all ps <.001) on all forms of loneliness for both men and women; both the youngest and oldest age-groups reported higher levels of both lacking companionships, feeling left out and feeling isolated (see Figure 2 for details). Table 1 shows the results from the logistic regression analyses. For example, compared to being 23-25 years old, female students aged between 18 and 20 years had 1.38 higher $O R, 95 \%$ CI $[1.29,1.48]$, of reporting that they lacked companionship. There were significant sex $\times$ age interactions for all three loneliness items (see Table 1 for more details). As detailed in Table 2, analysing the T-ILS total score continuously showed a similar pattern U-shaped, with small Cohen's $d$ effect-sizes. 


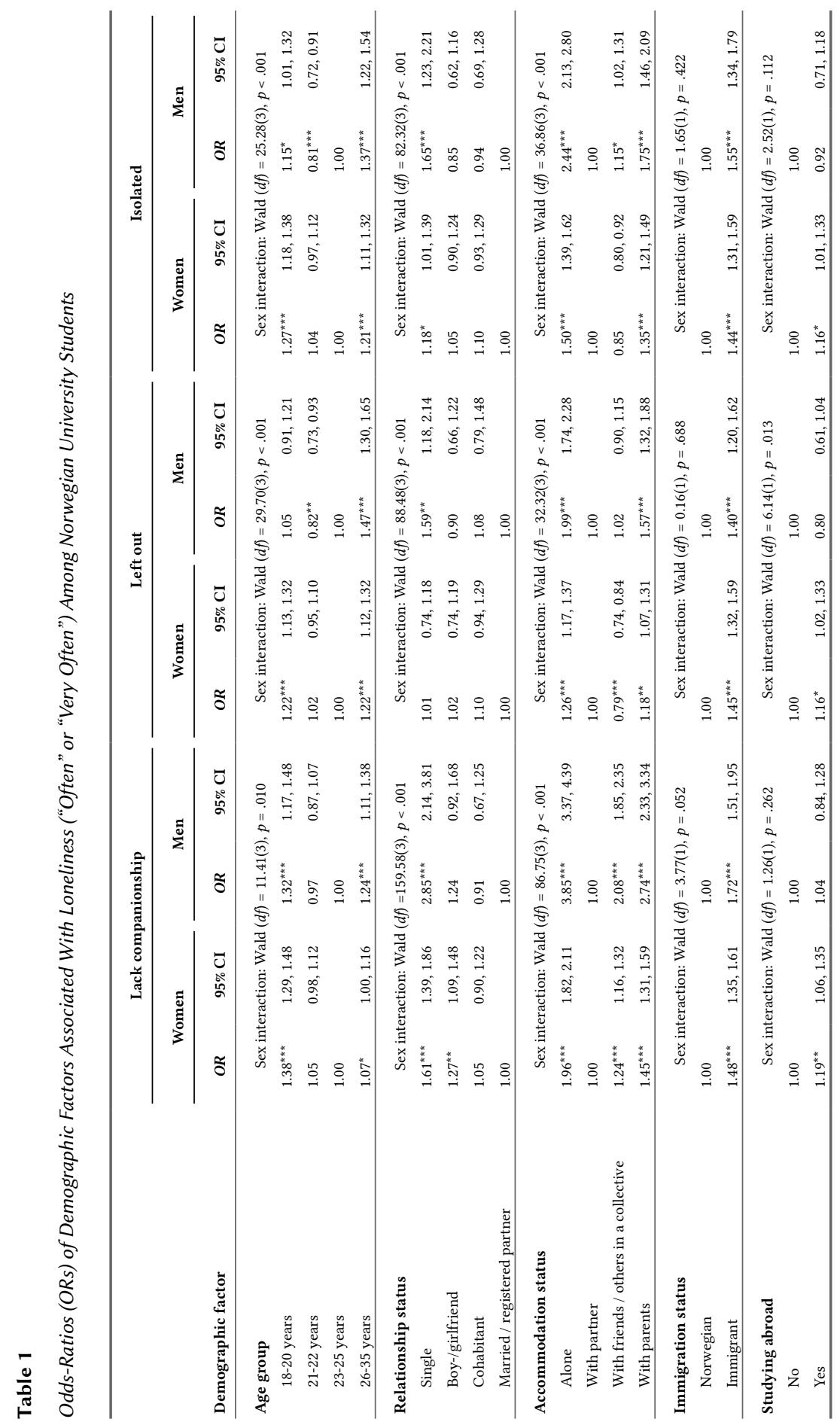




\section{Figure 2}

Loneliness Prevalence ("Often"/"Very Often”) Stratified by Age-Group in Male and Female Students

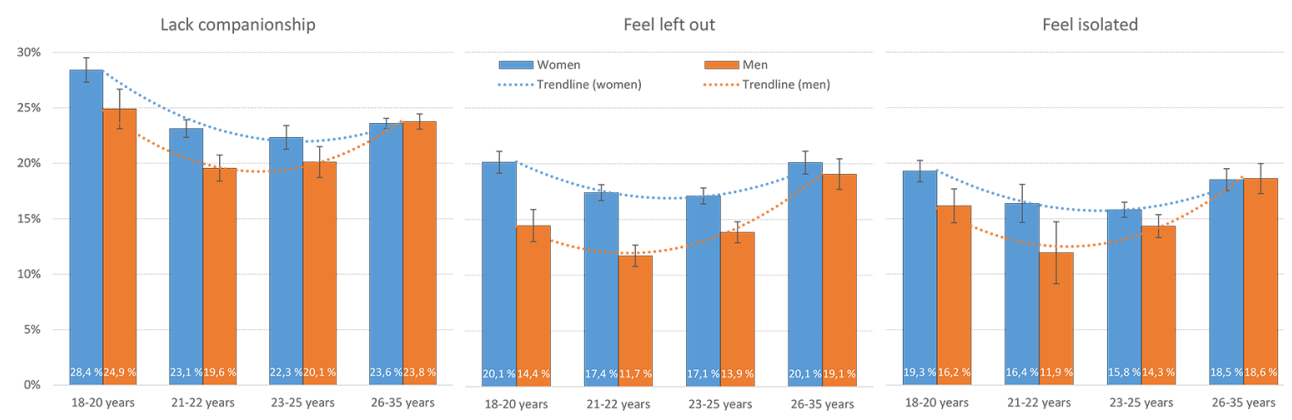

Note. The curves show the polynomial/curvilinear trendline (order 2).

Table 2

Demographic Factors Associated With Loneliness (T-ILS Sum Score) Among Norwegian University Students

\begin{tabular}{|c|c|c|c|c|c|c|}
\hline \multirow[b]{2}{*}{ Demographic factor } & \multicolumn{3}{|c|}{ Women } & \multicolumn{3}{|c|}{ Men } \\
\hline & $M$ & $S D$ & Cohen's $d^{a}$ & $M$ & $S D$ & Cohen's $d$ \\
\hline \multicolumn{7}{|l|}{ Age group } \\
\hline 18-20 years & 7.90 & 3.11 & 0.12 & 7.32 & 3.10 & 0.15 \\
\hline 21-22 years & 7.60 & 3.00 & 0.02 & 6.87 & 2.93 & Reference \\
\hline 23-25 years & 7.55 & 2.98 & Reference & 7.07 & 3.02 & 0.07 \\
\hline $26-35$ years & 7.66 & 3.19 & 0.04 & 7.50 & 3.26 & 0.20 \\
\hline \multicolumn{7}{|l|}{ Relationship status } \\
\hline Single & 7.78 & 3.05 & 0.17 & 7.62 & 3.15 & 0.36 \\
\hline Boy-/girlfriend & 7.58 & 3.00 & 0.10 & 6.53 & 2.78 & 0.01 \\
\hline Cohabitant & 7.52 & 3.08 & 0.08 & 6.52 & 2.88 & 0.01 \\
\hline Married / registered partner & 7.27 & 3.07 & Reference & 6.49 & 3.04 & Reference \\
\hline \multicolumn{7}{|l|}{ Accommodation status } \\
\hline Alone & 8.25 & 3.16 & 0.25 & 8.09 & 3.26 & 0.52 \\
\hline With partner & 7.49 & 3.07 & 0.01 & 6.48 & $(2.91)$ & Reference \\
\hline With friends / others in a collective & 7.47 & 2.92 & Reference & 7.02 & 2.92 & 0.18 \\
\hline With parents & 7.86 & 3.22 & 0.13 & 7.36 & 3.30 & 0.28 \\
\hline \multicolumn{7}{|l|}{ Immigration status } \\
\hline Norwegian & 7.61 & 3.03 & Reference & 7.08 & 3.05 & Reference \\
\hline Immigrant & 8.17 & 3.19 & 0.14 & 7.73 & 3.24 & 0.05 \\
\hline \multicolumn{7}{|l|}{ Studying abroad } \\
\hline No & 7.63 & 3.05 & Reference & 7.13 & 3.07 & Reference \\
\hline Yes & 8.03 & 2.99 & 0.13 & 7.24 & 2.84 & 0.04 \\
\hline
\end{tabular}

${ }^{a}$ Cohen's $d$ effect sizes (pooled $S D$ ) were calculated for each demographic variable using the category with the lowest T-ILS score (sex specific) as the reference group. 
When analyzing the association between age as a continuous variable and overall loneliness, similar findings were observed. There was a statistically significant quadratic (curvilinear) association between continuous age and overall loneliness, $F(2,48685)=$ $12.91, p<.001$, but there was no evidence of a significant linear association, $F(1,48686)=$ $1.48, p=.224)$.

\section{Loneliness and Relationship Status}

Single students reported more often that they lacked companionship compared to students with another relationship status, a tendency that was especially pronounced for single male students, $O R=2.85$; 95\% CI [2.14, 3.81], see Table 1 for details. And whereas feeling left out was also more prevalent in single male students, relationship status was not significantly associated with feeling left out in female students. In terms of feeling isolated, single male students reported higher levels of isolation, whereas relationship status was less clearly associated with feeling isolated in female students (see Figure 3 for details). There were significant sex $\times$ relationship interactions for all three loneliness items (all ps < .001). Analyses of the T-ILS total score showed a similar pattern (see Table 1 for details).

Figure 3

Loneliness Prevalence ("Often"/Very Often") by Relationship Status in Male and Female Students

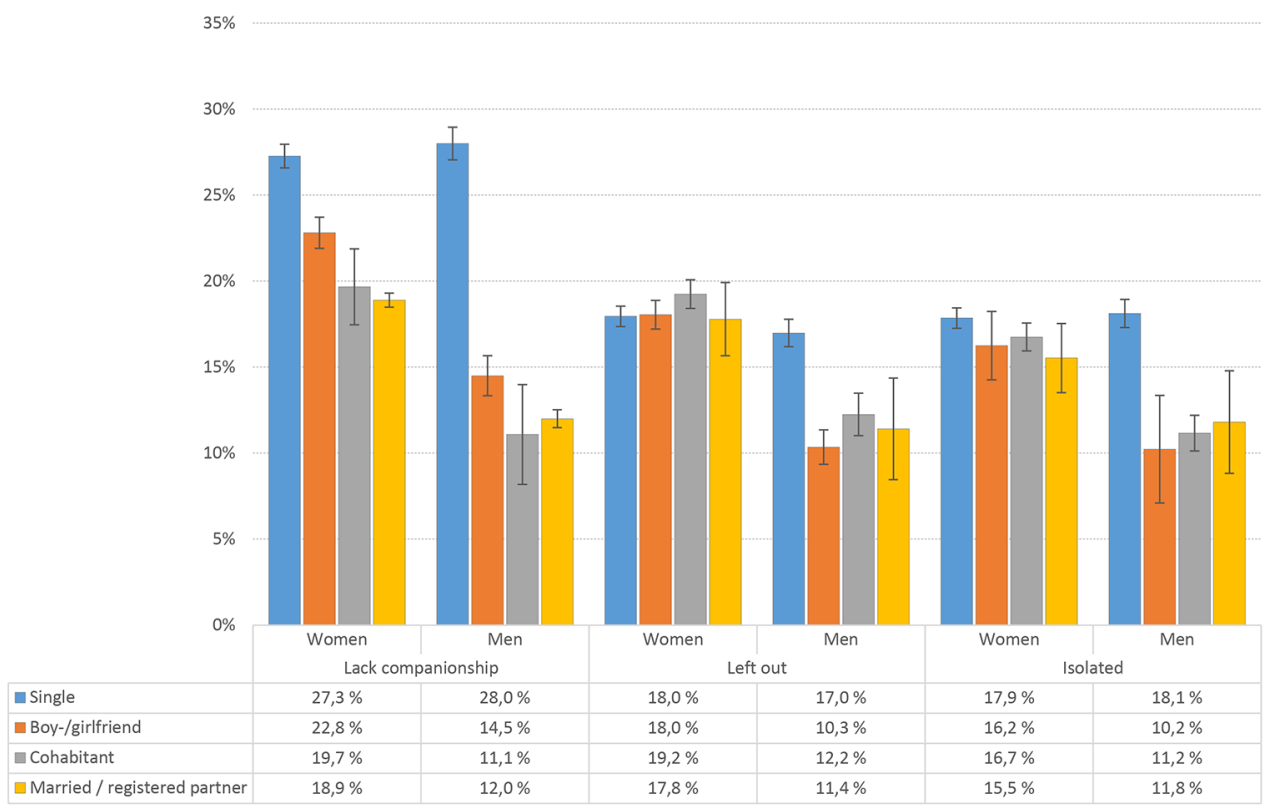

Note. Error bars represent $95 \%$ confidence intervals. 


\section{Loneliness and Accommodation Status}

Similar to the findings for relationship status, also accommodation status was significantly associated with loneliness. Both female and male, but especially male students living alone had the highest loneliness scores across all three items. Students living with their parents more often reported lacking companionship, feeling left out and isolated compared with students living with a partner/friends (see Figure 4 for details). There were significant sex $\times$ accommodation interactions for all three loneliness items (all ps <.001). Analyses of the T-ILS total score showed a similar pattern (see Table 1 for details).

\section{Figure 4}

Loneliness Prevalence ("Often"”"Very Often") by Accommodation Status in Male and Female Students

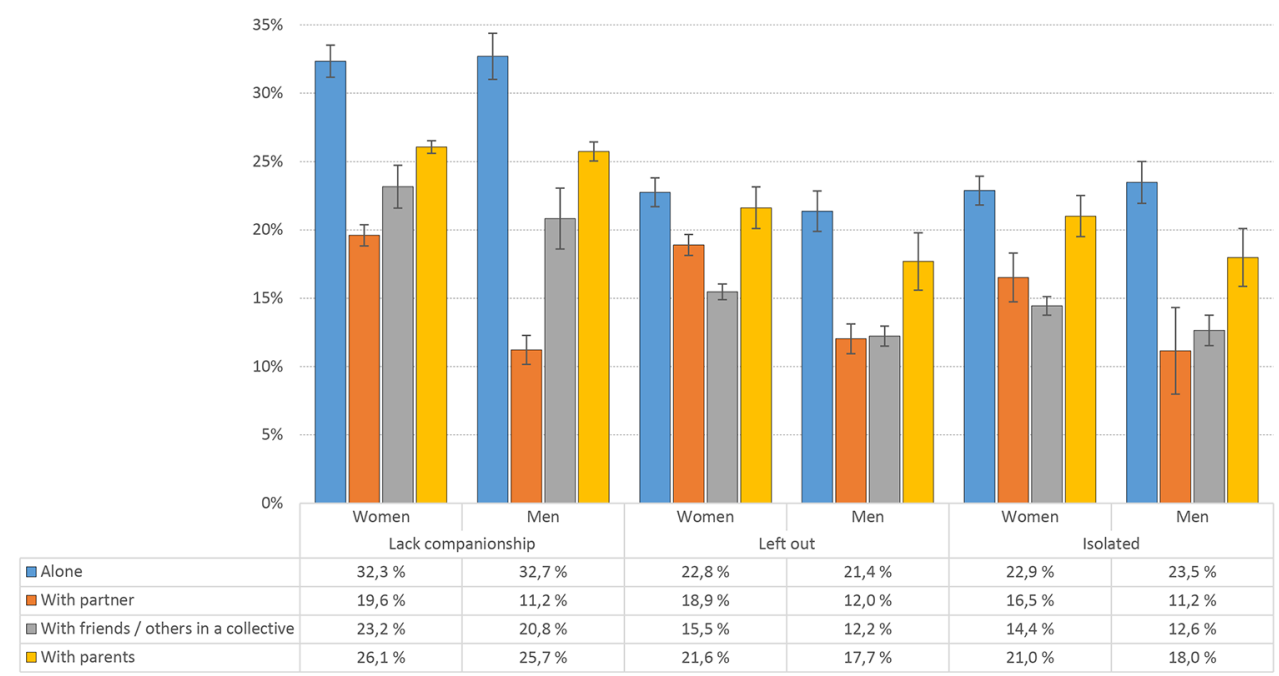

Note. Error bars represent $95 \%$ confidence intervals.

\section{Loneliness and Studying Abroad}

As detailed in Table 1, females students living/studing abroad had significantly higher odds of reporting loneliness across all three T-ILS items, whereas a similar pattern was not observed for male students. However, a significant sex $\times$ studying abroad interaction was only observed for "feeling left out" (see Table 1 for details).

\section{Trend of Loneliness From 2014 to 2018}

Figure 5 shows the prevalence of loneliness across from 2014 to 2018. There was a significant overall increase in students reporting feeling lonely ("quite a bit", or "extremely") 
from $2014(16.5 \%)$ to $2018(23.6 \% ; p<.001)$. The increase was evident in both men and women, and across both response categories (see Figure 5 for details).

\section{Figure 5}

Prevalence of Loneliness (From the HSCL-25) From 2014 to 2018 by Sex

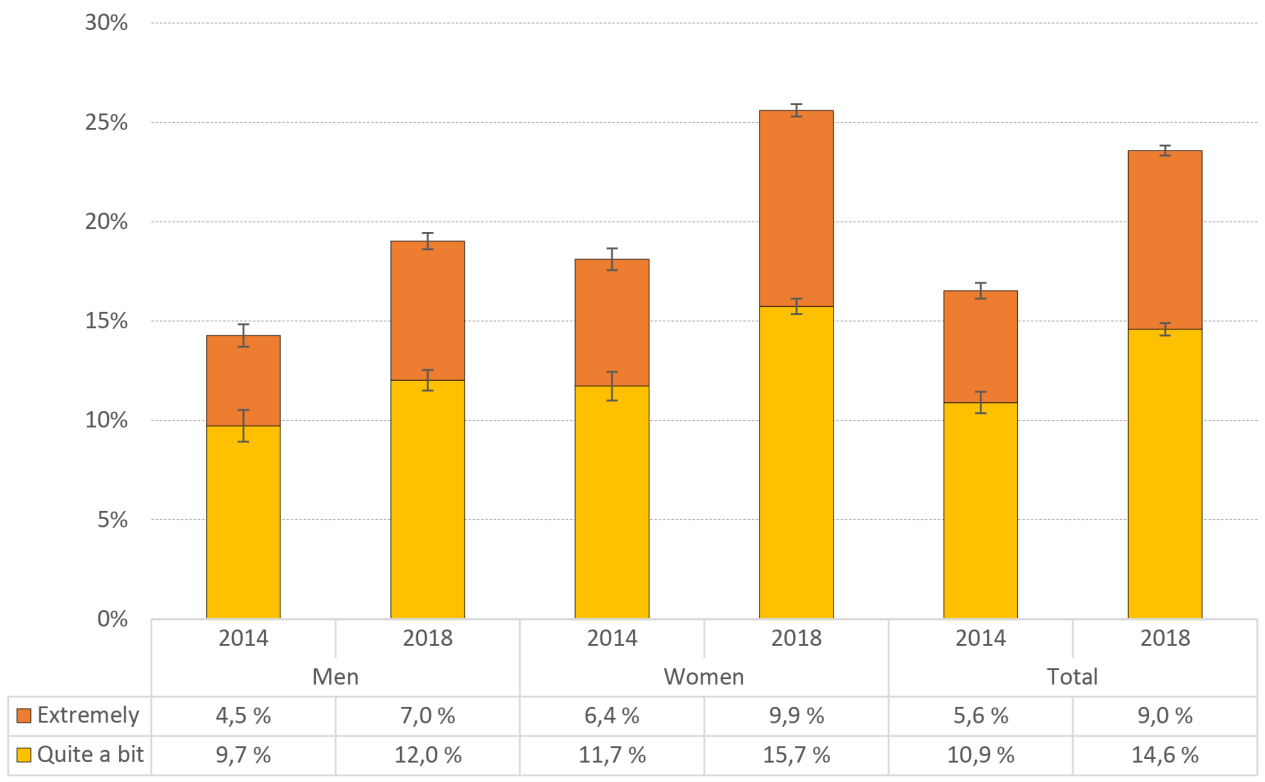

Note. Error bars represent 95\% confidence intervals.

\section{Discussion}

This large national survey from 2018 of Norwegian fulltime students found that feelings of loneliness were common. Age showed a curvilinear association with loneliness, with the youngest and oldest students reporting the highest level of loneliness across all indicators of loneliness. Other significant demographic determinants of loneliness were being female, single, living alone and studying abroad. There was a considerable increase in loneliness reported by the 2018 cohort compared to the 2014 cohort, and this effect was particular strong for males, for whom the proportion of feeling "extremely" lonely had more than doubled.

The findings confirm that loneliness is frequently experienced among college and university students, as indicated by $14-24 \%$ of the students responding that they "often" or "very often" lacked companionship, felt left out, or felt isolated. In line with a previous German study (Diehl et al., 2018), we found that loneliness peaked among the youngest students (aged between 18-20 years), possibly as a result of the transition to university 
life. However, a second peak in loneliness was found among the oldest age group (26-35 years). This may be related to a second transitional period towards the end of the studies, in preparation for moving into full-time work. It may also be that these individuals are establishing new relationships after a transition into work and they identify less with student life and are spending less time in student social activities at this stage.

Being in a close relationships was associated with less loneliness among the students, comparable to the protective effect of close relationships in the general population (Beutel et al., 2017). For students, their living situation is a period-specific buffer against loneliness, with students sharing accommodation reporting less loneliness than those that live alone, a finding which also is in line with a previous German university study (Diehl et al., 2018).

The complex associations between sex and loneliness may be understood in light of the inconsistencies in sex differences in previous studies (Mahon et al., 2006). The general pattern is that female students report more loneliness than men across most categories, especially in the younger age groups, while the difference is attenuated in the oldest student group. Some risk factors had differential effects across sexes, including a stronger association between relationship status and loneliness among men, with single men being a noteworthy high-risk group. Similarly, living alone was also a stronger risk factor for men than women. Overall, it seems that men are more sensitive to the structural factors and relationship status for loneliness than females. This may also indicate that interventions should be attentive toward sex-specific risks, and it might be that differential interventions are needed. Future interventions studies could explore if men show a more beneficial more effect of structural interventions such as organised activites and housing, while women might respond better to strengthening social relationships. Women reporting more loneliness than men may also be a result of woman may more easily acknowledging feelings of loneliness, due to less social consequences of lonliness for woman (Borys \& Perlman, 1985).

We found a substantial increase in reported loneliness from 2014 to 2018 . While there is limited studies reporting on trends, a Danish study found a similar pattern from 1991 to 2014 among adolescents (Madsen et al., 2019). The effect in that study was strongest for the high SES groups. Although we have no information on family SES in the current study, all the included participants are pursuing higher education. Two studies of elderly have reported an opposite pattern, with loneliness decreasing over time (Honigh-de Vlaming et al., 2014; Lempinen, Junttila, \& Sourander, 2018), but it might very well be that the trends are different across age groups, and this limits the comparison. The recency of the present study also precludes comparison to others in the same time period. It is uncertain if this is an ongoing trends, but the next planned wave of the SHoT study in 2022 will give new and valuable information on the longer trajectories of loneliness over time. What the drivers of this increase may be is also uncertain. It may reflect a general increase in mental distress, with recent evidence from the same dataset 
as the current study showing that both sleep problems and self-harm have increased across the same time period (Sivertsen, Hysing, et al., 2019; Sivertsen, Vedaa, et al., 2019).

The generalizabilty of the findings to the whole student population should be done with care given the relatively modest response rate for the SHoT2014 (29\%) and SHoT2018 (31\%). In relation to this, the issue of sample comparability is important. As the surveys in 2014 and 2018 included somewhat different welfare organizations and institutions, a recent report using the same datasets, performed detailed sensitivity analyses of the HSCL-25, comprising only institutions that were included in both surveys (Knapstad et al., 2019). The results from these analyses showed near-identical effect-sizes of the trend data, suggesting that the two samples from 2014 and 2018 are comparable.

Regarding the representativeness of the sample in comparison to the total student population in Norway, the SHoT2018 study consisted of $69 \%$ females, compared to $58 \%$ of all those who were invited. As such, this may represent a bias for the overall estimates, which is why we mainly present gender-specific results. In contrast, the age distribution was almost identical between the invited and the participating student, thus supporting the representativeness of the sample (Sivertsen, Vedaa, et al., 2019). Rather, it may be more appropriate to emphasize the relative differences between men and women, as well as different age cohorts and sociodemographic factors found in the current study, as these estimates are less prone to selection bias. The cross-sectional nature of the SHoT2018-study precludes conclusions on temporal order and causality. For instance, being lonely might reduce the chances for cohabiting, and thus loneliness might be a predictor of accomodation status and not its consequence. The loneliness measure is a three item, psychometrically sound measure, but a more nuanced understanding could have been gained by a more thorough assessment.

Future studies should investigate risk and protective factors for loneliness over and beyond demographic characteristics. Both individual characteristics of the students as well as systemic characteristics of the teaching situation should be investigated to increase our understanding of what constitutes risks for loneliness in this group to inform preventive interventions. The digital society may be one aspect that could account for the increase in loneliness and should be investigated further (Odacı \& Kalkan, 2010) Further, if the trend of increasing loneliness will further strengthen in the coming years or will attenuate should be investigated in the present study as well as other epidemiological studies of students

The findings also have notable implications. The rise in loneliness over a four year period warrants concern, and should be met with preventive actions. The demographic determinants identified in this study could give indications of high risk groups to target, including the transitional periods and those living alone. There might be a need for interventions to target male and female students diffentially. 
Funding: SHoT 2018 has received funding from the Norwegian Ministry of Education and Research (2017) and the Norwegian Ministry of Health and Care Services (2016).

Competing Interests: The authors have declared that no competing interests exist.

Acknowledgments: We wish to thank all students participating in the study, as well as the three largest student welfare organizations in Norway (SiO, Sammen, and SiT), who initiated and designed the SHoT study.

\section{References}

Beutel, M. E., Klein, E. M., Brähler, E., Reiner, I., Jünger, C., Michal, M., . . Tibubos, A. N. (2017). Loneliness in the general population: Prevalence, determinants and relations to mental health. BMC Psychiatry, 17(1), Article 97. https://doi.org/10.1186/s12888-017-1262-x

Borys, S., \& Perlman, D. (1985). Gender differences in loneliness. Personality and Social Psychology Bulletin, 11(1), 63-74. https://doi.org/10.1177/0146167285111006

Cacioppo, S., Grippo, A. J., London, S., Goossens, L., \& Cacioppo, J. T. (2015). Loneliness: Clinical import and interventions. Perspectives on Psychological Science, 10(2), 238-249. https://doi.org/10.1177/1745691615570616

Cohen, J. (1988). Statistical power analysis for the behavioral sciences (2nd ed.). Mahwah, NJ, USA: Lawrence Erlbaum.

Dahlberg, L., Agahi, N., \& Lennartsson, C. (2018). Lonelier than ever? Loneliness of older people over two decades. Archives of Gerontology and Geriatrics, 75, 96-103.

https://doi.org/10.1016/j.archger.2017.11.004

Derogatis, L. R., Lipman, R. S., Rickels, K., Uhlenhuth, E. H., \& Covi, L. (1974). The Hopkins Symptom Checklist (HSCL): A self-report symptom inventory. Behavioral Science, 19(1), 1-15. https://doi.org/10.1002/bs.3830190102

Diehl, K., Jansen, C., Ishchanova, K., \& Hilger-Kolb, J. (2018). Loneliness at universities: Determinants of emotional and social loneliness among students. International fournal of Environmental Research and Public Health, 15(9), Article 1865. https://doi.org/10.3390/ijerph15091865

Hayley, A. C., Downey, L. A., Stough, C., Sivertsen, B., Knapstad, M., \& Overland, S. (2017). Social and emotional loneliness and self-reported difficulty initiating and maintaining sleep (DIMS) in a sample of Norwegian university students. Scandinavian fournal of Psychology, 58(1), 91-99. https://doi.org/10.1111/sjop.12343

Holt-Lunstad, J., Smith, T. B., Baker, M., Harris, T., \& Stephenson, D. (2015). Loneliness and social isolation as risk factors for mortality: A meta-analytic review. Perspectives on Psychological Science, 10(2), 227-237. https://doi.org/10.1177/1745691614568352 
Honigh-de Vlaming, R., Haveman-Nies, A., Groeniger, I. B.-O., de Groot, L., \& van 't Veer, P. (2014). Determinants of trends in loneliness among Dutch older people over the period 2005-2010. Journal of Aging and Health, 26(3), 422-440. https://doi.org/10.1177/0898264313518066

Hughes, M. E., Waite, L. J., Hawkley, L. C., \& Cacioppo, J. T. (2004). A short scale for measuring loneliness in large surveys: Results from two population-based studies. Research on Aging, 26(6), 655-672. https://doi.org/10.1177/0164027504268574

Knapstad, M. S. B., Sivertsen, B., Knudsen, A. K., Smith, O. R. F., Aarø, L. E., Lønning, K. J., \& Skogen, J. C. (2019). Trends in self-reported psychological distress among college and university students from 2010 to 2018. Psychological Medicine. Advance online publication. https://doi.org/10.1017/S0033291719003350

Lempinen, L., Junttila, N., \& Sourander, A. (2018). Loneliness and friendships among eight-year-old children: Time-trends over a 24-year period. fournal of Child Psychology and Psychiatry, and Allied Disciplines, 59(2), 171-179. https://doi.org/10.1111/jcpp.12807

Luhmann, M., \& Hawkley, L. C. (2016). Age differences in loneliness from late adolescence to oldest old age. Developmental Psychology, 52(6), 943-959. https://doi.org/10.1037/dev0000117

Madsen, K. R., Holstein, B. E., Damsgaard, M. T., Rayce, S. B., Jespersen, L. N., \& Due, P. (2019). Trends in social inequality in loneliness among adolescents 1991-2014. Fournal of Public Health, 41(2), e133-e140. https://doi.org/10.1093/pubmed/fdy133

Mahon, N. E., Yarcheski, A., Yarcheski, T. J., Cannella, B. L., \& Hanks, M. M. (2006). A meta-analytic study of predictors for loneliness during adolescence. Nursing Research, 55(6), 446-447. https://doi.org/10.1097/00006199-200611000-00009

Matthews, T., Danese, A., Caspi, A., Fisher, H. L., Goldman-Mellor, S., Kepa, A., . . Arseneault, L. (2019). Lonely young adults in modern Britain: Findings from an epidemiological cohort study. Psychological Medicine, 49, 268-277. https://doi.org/10.1017/S0033291718000788

McWhirter, B. T. (1997). Loneliness, learned resourcefulness, and self-esteem in college students. Journal of Counseling and Development, 75(6), 460-469. https://doi.org/10.1002/j.1556-6676.1997.tb02362.x

Mounts, N. S. (2004). Contributions of parenting and campus climate to freshmen adjustment in a multiethnic sample. Journal of Adolescent Research, 19(4), 468-491. https://doi.org/10.1177/0743558403258862

Odac1, H., \& Kalkan, M. (2010). Problematic Internet use, loneliness and dating anxiety among young adult university students. Computers \& Education, 55(3), 1091-1097. https://doi.org/10.1016/j.compedu.2010.05.006

Portnoy, E. (1983). [Review of the book Loneliness - A sourcebook of current theory, research and therapy, by L. A. Peplau \& D. Perlman (Eds.)]. The Gerontologist, 23(3), 329-330.

Sivertsen, B., Hysing, M., Knapstad, M., Harvey, A. G., Reneflot, A., Lønning, K. J., \& O’Connor, R. C. (2019). Suicide attempts and non-suicidal self-harm among university students: Prevalence study. BfPsych Open, 5(2), Article e26. https://doi.org/10.1192/bjo.2019.4 
Sivertsen, B., Råkil, H., Munkvik, E., \& Lønning, K. J. (2019). Cohort profile: The SHoT-study, a national health and well-being survey of Norwegian university students. BMF Open, 9(1), Article e025200. https://doi.org/10.1136/bmjopen-2018-025200

Sivertsen, B., Vedaa, Ø., Harvey, A. G., Glozier, N., Pallesen, S., Aarø, L. E., . . Hysing, M. (2019). Sleep patterns and insomnia in young adults: A national survey of Norwegian university students. fournal of Sleep Research, 28(2), Article e12790. https://doi.org/10.1111/jsr.12790

\section{EACLIPT}

Clinical Psychology in Europe (CPE) is the official journal of the European Association of Clinical Psychology and Psychological Treatment (EACLIPT).

\section{(4) leibniz-psychology.org}

PsychOpen GOLD is a publishing service by Leibniz Institute for Psychology Information (ZPID), Germany. 